\title{
Assessment of technogenic pollution of Kyiv (Ukraine) with spectral reflectal characteristics of Tilia cordata Mill. (Tiliaceae) leaves
}

\author{
Vitaliy B. Nebesnyy, Anna A. Grodzinskaya \\ Institute for Evolutionary Ecology of the National Academy of Sciences of Ukraine, 03143 Kyiv, Lebedeva Str. 37, Ukraine \\ E-mail address (corresponding author): nebvit@gmail.com
}

\begin{abstract}
Complex estimation of industrial pollution in Kyiv using spectrophotometric method for measuring the reflection characteristics of bioindicator species Tilia cordata Mill. leaves was held. As the most informative indicator that determines the state of the plant (by inhibition of the photosynthesis), we selected index of stress (reverse vegetation index). At low values of the index of stress the productivity of photosynthesis is higher and respectively the state of the ecosystem as a whole is better. The spectral reflective coefficients of $T$. cordata leaves were measured in green - R1 (551.9 nm), red - R2 $(656.8 \mathrm{~nm})$ and near infrared - R3 $(802.0 \mathrm{~nm})$ the spectrum zones. The measured spectral reflective coefficients in these ranges were from 0 to 1 . Studies on reflective characteristics of more than 500 samples of $T$. cordata leaves from 17 habitats in 7 administrative districts of Kyiv has revealed the trend of increasing index of stress on the gradient of the traffic intensity. On the base of obtained results it is recommended the using of this method for monitoring of environmental quality, the possibility of rapid assessment of current environmental changes. In perspective the offered spectrophotometric method will do possible researches on responses of vegetation to the effect of natural and technogenic stressors at different phases of plant degradation each of that has the own mechanism.
\end{abstract}

KEY WORDS: Tilia cordata Mill, urban ecosystems, technogenic contamination, stress index

\section{Introduction}

Urban areas differs by its peculiarity of ecological factors, complex of technological impacts leading to a significant environmental transformation. Modern approaches of estimation of quality of natural environments (air, soils, and water) must be oriented, foremost, on biotic indexes. Chemical analyses, as known, only represent the presence of "markers" - certain concentrations of pollutants, that limits the estimation of the state of living organisms, groupments and ecosystems, on the whole (BIOINDICATION..., 2013). Biondication, as an effective and inexpensive method for the biological monitoring, in the last decades became popular and got a wide application. The degree of influence of external factors is estimated by the state, changes of physiology, biochemical, functional, citogenetics and other indexes of different bioindicators (among them there are plants, algae, mushrooms, lichens, invertebrates, insects etc.).
Plants are considered reliable indicators of the environmental pollution with toxic substances because they are forced to adapt to stress through physiological, biochemical and anatomical and morphological alteration.

Fixing and evaluation of these changes may be registered at the earliest stages of degradation, give a reliable picture of plant growth conditions showing the state of the urban environment (Maydebura, 2006; NikOlaEVSKYI, 1999; DidukH, 2012). In last decades, increasing the impact of negative factors inherent in urban areas leads to a weakening of vegetation, premature aging, reduce productivity, defeat diseases, pests, and finally to the death of plants. It is considered that above ground organs of plants, and in particular leaves, in a most degree added negative influence of contamination in a city. Numerous researches specify that the main source of negative influence on vegetable organisms is a intensive traffic (CHAUHAN, 2010; KARDEL ET AL., 2011). KARDEL with 
coauthors noted that a reaction on contamination influence is species-specific and to a great extent determined descriptions of surface of leaf (KARDEL ET AL., 2011). At the same time among the number of contaminants especially important are heavy metals such as mercury, lead, copper, nickel, cadmium, arsenic, zinc. which is explained with high rates of their accumulation in the environment. In the city of Kyiv the total amount of technogenic deposits (the moved soils, different wastes, garbage with harmful and toxic substances) grows constantly, annual quantity of domestic wastes reaches millions of $\mathrm{m}^{3}$ (SAMCHUK \& OGAR, 2012). Number of clean areas and parks within the city and the surrounding areas become less and less, and they are gaining in value (ANDREEVA ET AL., 2006a).

The most common and dangerous for the ecological condition of soil and water is a heavy metals pollution of urban territories. It is known that in soil salts of heavy metals often leads to loss of plant communities (ARTAMONOV, 1986). The result of air and soil pollution is a change of the pigment composition of plants, which, in turn, appears as change of the optical characteristics (ANDREEVA ET AL., 2006b). It also is changing spectral reflective characteristics of vegetation that allows them to bioindication technogenic pollution levels. Thus there are also changes of spectral reflective characteristics of vegetation that allows to use them for bioindication of technogenic pollution levels. Complex analysis of these changes may serve as a basis for the development of remote methods of diagnosis of the condition urban ecosystems (ANDREEVA ET AL., 2006b, 2007). Moreover, a number of researchers proved a relationship between the change of the optical parameters of green plants and their physiological state. In particular it was found that spectral reflection coefficients of green leaves correlate with their photosynthetic activity (KONDRATYEV \& FEDCHENKO, 1982; LEVANCHUK ET AL., 2005). Since the process of photosynthesis is very sensitive to environmental factors, the change in the intensity can be seen as a plant response to stressors, in particular air pollution (ANDREEV, 2013; KHAVANINZADEH ET AL., 2014). The aim of our study was to assess the state of bioindicator Tilia cordata Mill., growing within the city of Kyiv by analyzing changes in the spectral reflective characteristics.

\section{Material and methods}

Over 500 samples of T.cordata leaves from 17 habitats (with different degrees of anthropogenic and technogenic pollution) within the city of Kyiv have been studied (Fig. 1). For a comprehensive assessment of anthropogenic impact spectrophotometric method, based on the measurement of biological responses of plants was used (LEVANCHUK ET AL., 2005; LUTSYSHYN ET AL., 2010). For registration of these reactions it was used a field spectrophotometer (PF-8), which can selectively measure a reflect radiation energy in specific parts of the spectrum. The spectral photometer ranges are chosen as follows so that they correspond to the basic physiological processes that occur in plants (SURIN, 1998).

In order to analyze the state of plants and a suppression of photosynthesis degree we selected an index of stress (a reverse vegetation index) as a good informative indicator. In fact today there are about 160 different vegetation indexes (ChEREPANov \& DRUZHININ, 2009). They were chosen experimentally (empirically) on the base of the known spectral curves characteristics of vegetation and soils reflectivity. Mainly the calculation of the vegetation indexes based on some of the most stable, not depended of other factors, the spectral curve parts of an reflective plants capacity. In the range of red zone $(620-750 \mathrm{~nm})$ are the absorption maximum of solar radiation by chlorophyll, in the range of green zone $(550 \mathrm{~nm})$ the reflection associated with the pigment composition of leaf, and near infrared (750-1300 nm) - the maximum reflection energy of leaf's cell structure. The literature data confirmed that a high photosynthesis activity (associated as usual with an increasing of phytomass) leads to a lower reflection coefficients in the red zone of the spectrum and a greater value in the near infrared. The ratio of these parameters to let clearly separate the vegetation from other natural objects (CHEREPANOV \& DrUZHININA, 2009; MotohKA ET AL., 2010).

The spectral reflective coefficients (SRC) of T. cordata leaves were measured in green - R1 $(551,9 \mathrm{~nm})$, red - R2 $(656,8 \mathrm{~nm})$ and near infrared - R3 $(802,0 \mathrm{~nm})$ the spectrum zones. The measured spectral reflective coefficients in these ranges were from 0 to 1 . The measurement error was about $2.3 \%$. The index of stress was defined on the base of measurements as:

$$
\mathrm{IC}=\mathrm{R} 1 / \mathrm{R} 3,
$$

which numerically characterizes the degree of the plants inhibition (SURIN, 2011). 


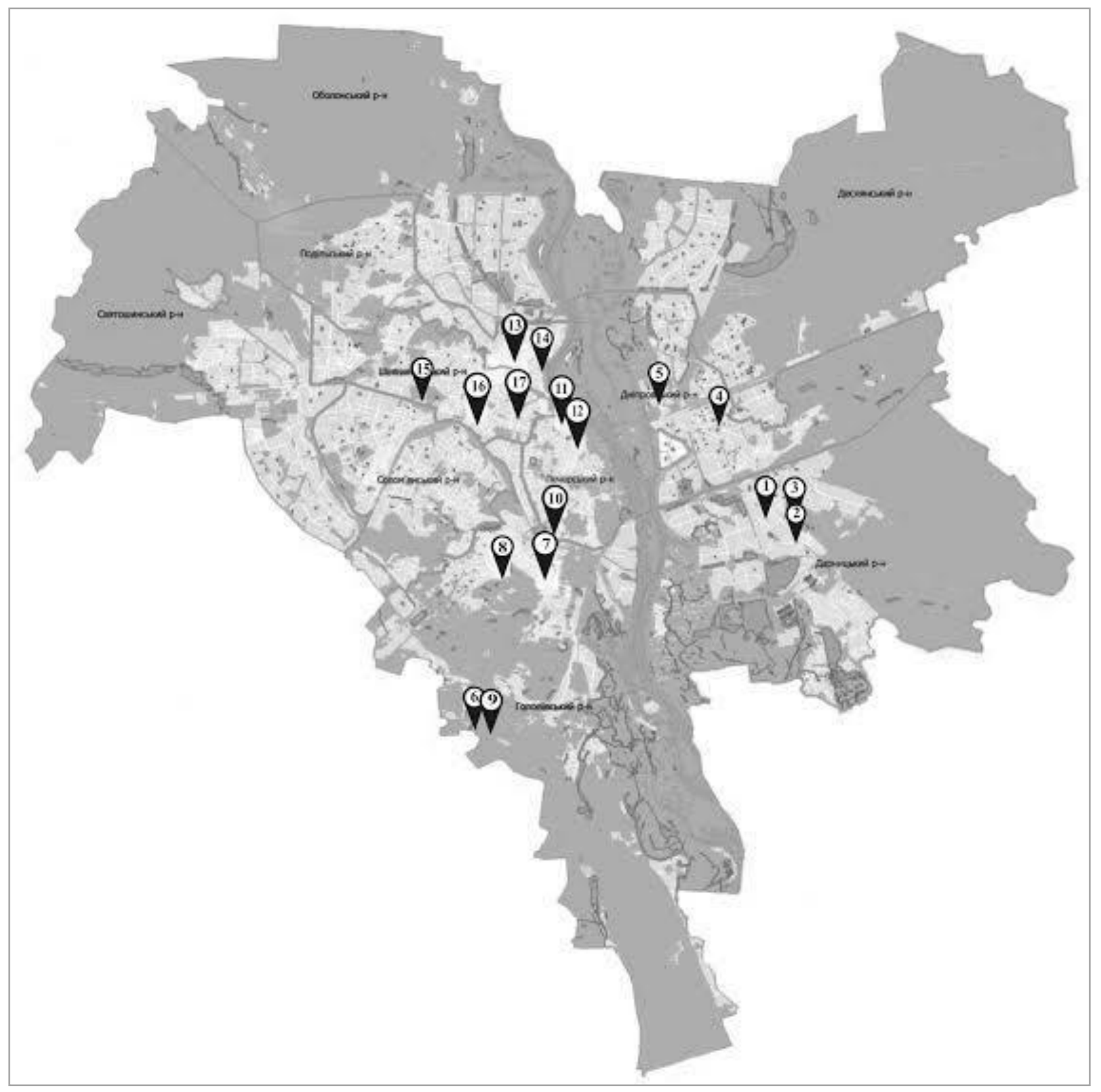

Fig. 1. Sampling sites in Kyiv (2014)

Darnitsky district - (1) Arhitektor Verbytskyi Str., 6; (2) Harkiv highway 180/21; (3) Harkiv highway, 129; Desnyansky district - (4) Magnitogorska Str., 1 (JSC"Himvolokno"); Dniprovskiy district - (5) Lunacharsky Str.; Golosiïvsky district (6) Metrologichna Str., 4-12; (7) Nauki Ave., 32; (8) Golosiïvsky Ave., 88; (9) Park "Theophany"; Pecherskyi district - (10) Druzhby Narodiv Blvd.; (11) Grushevskogo Str., 6; (12) Mariinsky Park; Podilsky district - (13) Verhniy Val St., 4-6; (14) Naberezhno- Hreschatitska Str., 35 and Horiva Str., 50; Shevchenkivskyi district - (15) Pushkin park; (16) Peremogi Ave., 4; (17) Khreschatyk Str.( cross with Prorizna Str.).

\section{Results}

The selected index of stress (IS) on the one hand is the indicator of the state of the plant, and the other, expresses the degree of anthropogenic impact on the plants (and, finally, on habitats). This parameter is particularly suitable for the study of the complex anthropogenic influence on the ecosystem. At low values of IS the productivity of photosynthesis is higher and respectively the state of the ecosystem as a whole is better.
For monitoring we selected sampling sites with a different predictable intensity of anthropogenic activity. Studies have shown that habitat with heavy traffic load (Nauki Ave., Peremogi Ave., Naberezhno-Khreschatytska Str., Holosiivskyi Ave.) and Hrushevskyi Str., (where during the February events in 2014 was man-made pollution by combustion products tires) are areas of strong contamination. The indexes of stress in these areas were in the range of 0.230 to 0.240 (Fig. 2). 


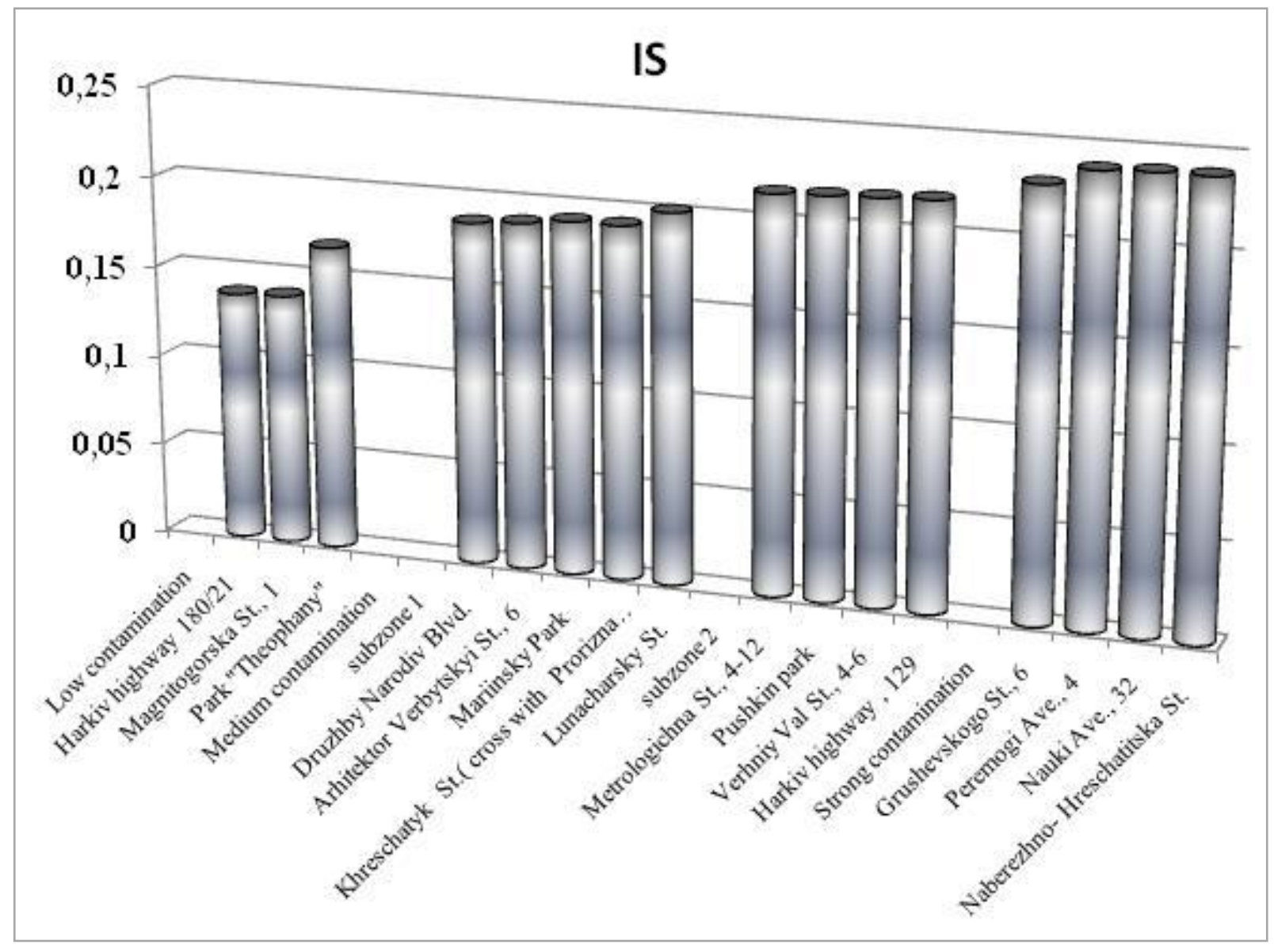

Fig. 2. Anthropogenic press zoning of Kyiv with a stress index (2014)

The areas with medium pollution were divided into two subzones, the first of which include Metrologichna Str., Verhniy Val Str., Kharkiv highway (along the highway) and Pushkin Park - with the index of stress values from 0.215 to 0.219 . It should be noted that primarily to the measurement we considered Pushkin Park as an area of potentially weak anthropogenic load. However, the data obtained has shown a significant impact on the selected bioindicator (T. cordata) that the object is located close to Peremogi Ave., and an industrial zone of the plant "Bolshevik" (the IS was 0.216). For the second subzone - Druzhby Narodiv Blvd., Khreschatyk Str., Mariinsky Park, Lunacharsky Str., Architector Verbitsky Str., the index of stress was in the range of 0.187 to 0.201 .

Low levels of anthropogenic load of IS was found at Kharkiv highway (the distance from the road was around $20 \mathrm{~m}$, in the yard near the house), Magnitogorska Str. and Park of landscape art "Theophany" there IS value ranged from 0.137 to 0.167.

So the results of the study of spectral reflective characteristics of species bioindicator (Tilia cordata) revealed a tendency to increase the gradient index of stress with an intensity of traffic flow in the city of Kyiv. Therefore, the environment bioindication with spectral characteristics of T. cordata leaves) is perspective (in citu) method for control of environmental conditions.

At the same time, the problem of choose a convenient and reliable model object for bioindication is always important. Taking into account a crisis level of anthropogenic contamination of Kyiv with several pollutants (heavy metals, radionuclides, technical salt, etc.), in our opinion, a complex of bioindicator species need to be used.

\section{Conclusions}

Research on spectral reflective characteristics of bioindicator $T$. cordata revealed a tendency to increase the gradient of the index of stress with an intensity of traffic flows in the city of Kyiv.

The data obtained allow to recommend the method of the plant index stress for environmental monitoring and estimation of the environmental quality, the ability to assess of environmental changes and to respond timely to any negative technogenic influences. 
In perspective the method makes it possible to study responses of plants to the effect of natural and technogenic stressors and an adaptive diagnosis phase, a phase of stability and phases of excited irreversible changes, each of which has its own physiological mechanisms of oppression and patterns of accumulation of pollutants based on optical measurements.

Meaning a danger of actual crisis level of anthropogenic contamination of Kyiv with several known and unknown pollutants (heavy metals, radionuclides, technical salt, etc.), a complex of bioindicator species (plants, mushrooms and insects) need to be used.

\section{References}

Andreeva A.V., Buznikov A.A., Timofeev A.A., AlekseevaPopova N.V., Belyaeva A.I. 2006a. Evaluation of the ecological state of environment with a reflection spectruma of indicator species of vegetation. Actual Problems of Remote Sensing of the Earth from Space: physical bases, methods and technologies for monitoring of environment, potentially dangerous phenomena and objects. Coll. scientific articles, II, 3: 265-270 [in Russian].

Andreeva A.V., Buznikov A.A., Timofeev A.A., Scriabin S.V. 2006b. Spectral studies of anthropogenic impact on vegetation of megapolisis. News of St.-Petersburg ETU "LETI". 1: 31-38 [in Russian].

Andreeva A.V., Buznikov A.A., Scriabin S.V., Timofeev A.A., Alekseeva Popova N.V., Belyaeva A.I. 2007. Investigation of the nature of changes in the optical characteristics of the vegetation under the influence of heavy metals for the development of diagnostics pollution method. Actual Problems of Remote Sensing of the Earth from Space, 2, 4: 175-182 [in Russian].

Andreev D.N. 2013. Bioindication of environment with a chlorophyll fluorescence of needles of Scots pine. Bioindication in ecological assessment of soils and related habitats. Proc. rep. Int. Conf.. Moscow, February 4-6 [in Russian].

Artamonov V.I. 1986. Plants and purity of the natural environment. M. Nauka [in Russian].

Bioindication in ecological assessment of soils and related habitats. Book of Abstracts of the Int. Conf., Moscow, 4-6 February 2013. Moscow, 2013.
Chauhan A. 2010. Photosynthetic pigment changes in some selected trees induced by automobile exhaust in Dehradun, Uttarakhand. New York Sci. J., 3: 45-51.

Cherepanov A.S., Druzhinin E.G. 2009. Spectral properties of plants and vegetation indices. Geomatics, 3: 28-32 [in Russian].

Diduh Ya.P. 2012. Basics of bioindication. K.: Naukova Dumka [in Ukrainian].

Kardel F., Wuyts K., Maher B.A., Hansard R., \& Samson R. 2011. Leaf saturation isothermal remanent magnetization (SIRM) as a proxy for particulate matter monitoring: inter-species differences and in-season variation. Atmospheric Environ., 45 (29), 5164-5171.

Khavaninzadeh A.R., Veroustraete F., Buytaert J.A.N., Samson R. 2014. Leaf injury symptoms of Tilia sp. as an indicator of urban habitat quality. Ecol. indicators, 41: 58-64.

Kondrat'ev K.Ya., Fedchenko P.P. 1982. The spectral reflectance and recognition of vegetation. L: Gidrometeoizdat [in Russian].

Levanchuk A.V., Kopytenkova O.I., Nehoroshev A.S., Gayko I.I. 2005. Method of monitoring of habitat quality in the city. Successes of actual sci., 9: 59-61 [in Russian].

Lutsyshyn O.G., Radchenko V.G., Palapa N.V., Yavorovsky P.P. 2010. Macromorphological change of response reaction of woody plant from street of Kiev metropolis stands at stress levels of anthropogenic pollution. Reports of NAS of Ukraine, 6: 180-187 [in Ukrainian].

Maydebura I.S. 2006. The influence of air pollution of Kaliningrad on the anatomical - morphological and biochemical indices of woody plants. Ph D Thesis for biol. Sci. Kaliningrad [in Russian].

Motohka T., Nasahara K.N., Oguma H., Tsuchida S. 2010. Applicability of Green-Red Vegetation Index for Remote Sensing of Vegetation Phenology. Remote Sensing, 2: 2369-2387.

Nicholaevskyi V.S. 1999. Ecological assessment of environmental pollution and the state of terrestrial ecosystems with phytoindication methods. [in Russian].

Samchuk A.I., Ogar T.V. 2012. Features of distribution of oligoelements in the natural and technogenic landscapes of Ukraine. [in:] Ecological and geochemical research of environmental objects of Ukraine. Zhovinskyi E.Ya, Kuraeva I.V. (eds). K.: Alpha-reklama: 95-104.

Surin V.G. 1998. Field precision photometry method for interpretation of geochemical anomalies. Investigat. of Earth from Space, 4: 38-44 [in Russian].

Surin V.G. 2011. Active optical testers for information providing for precision agriculture, animal husbandry and environmental safety. Agrophysics, 2: 39-49 [in Russian]. 